\title{
TEM identification of Pseudo-nitzschia species from Lisbon Bay (NE Atlantic)
}

\author{
A. Amorim*, V. Veloso*, B. Frazão* and A.P. Alves de Matos** \\ ${ }^{*}$ FCUL, Instituto de Oceanografia, 1749-016 Lisboa, Portugal \\ ** Serviço de Anatomia Patológica, Hospital Curry Cabral, Rua da Beneficência 8, 1069-166 Lisboa e \\ FCUL, Centro de Biologia Ambiental, 1749-016 Lisboa, Portugal \\ ajamorim@fc.ul.pt
}

Several species of the chain-forming marine diatom genus Pseudo-nitzschia produce domoic acid (DA), a neuroexcitant amino acid, responsible for a human amnesic syndrome after consumption of toxified shellfish (ASP) [1]. Since 1995, the Portuguese monitoring program has regularly detected the presence of DA in shellfish. So far only P. australis has been implicated [2, and references therein]. Identification of the causative species of Pseudo-nitzchia in natural samples is hampered by difficulties in identification at the light microscope level. Recent studies have shown that ultrastructural details of the wall, observed by transmission electron microscopy, allow the identification of species in good agreement with the phylogenetic and biological species concept [3].

Here we present the identification of eight strains of Pseudo-nitzschia spp., isolated from Lisbon Bay and kept in culture at the algal culture collection of the University of Lisbon (ALISU), based on transmission electron microscopy (TEM). All cultures showed gross morphological changes with time, namely changes in size and shape, and in some cases colonies were no longer formed, rendering impossible the identification with light microscopy even of the most characteristic species. Samples were acid-cleaned following [4]. Drops of cleaned material were placed on formvar-carbon coated grids, dried, and studied in a JEOL 100SX electron microscope at magnifications up to 40000x. Permanent slides for LM were prepared by mounting aliquots of the same cleaned material in Napharx.

TEM revealed all major taxonomical details namely, central nodule, density of striae, fibulae and poroids and the ultrastructural details of the poroid vela. The studied strains were assigned to four different species based on the ultra-structure of the silica wall: $P$. australis (2 strains), $P$. fraudulenta (4 strains), P. multiseries (1 strain) and P. subpacifica (1 strain) (Figs 1-4). Our results show that cell wall ultra-structure details, revealed by TEM, allow unequivocal identification of Pseudo-nitzschia species, even when gross morphology is altered by culture conditions or life-cycle events. The toxicity of the identified species is still under investigation.

\section{References}

[1] Bates, S.S., Garrison, D.L., Horner, R. In: D. M. Anderson, A. D. Cembella, G. M. Hallegraeff (Eds.), Physiological ecology of harmful algal blooms. NATO ASI series, Vol. G.41, SpringerVerlag, Berlin, (1998) p. 265.

[2] Vale, P., Botelho, M. J., Rodrigues, S. M., Gomes, S. S., Sampayo, M. A. D. M. Harmful Algae 7 (1) (2008): 11 .

[3] Amato, A., Kooistra, W. H. C. F., Ghiron, J. H.L., Mann, D. G., Pröschold, T., Montresor, M. Protist 158(2) (2007): 193.

[4] Hasle, G. R., Syvertsen, E. E.. In: C. R. Tomas (Ed.), Identifing marine diatoms and dinoflagellates. Academic Press, San Diego, (1996) p. 5.

Research funded by FCT through Project HABCOL -PDCT/MAR/60086/2004. 
Fig.1. Pseudo-nitzschia subpacifica,(a) whole valve; central interspace visible (arrow) (bar=10 $\mu$ m); (b) detail of striae with 2 rows of poroids with simple vela (bar $=0,2 \mu \mathrm{m})$. Fig. 2 . P. australis (a) valve at low magnification with detail of valve ending, central interspace absent (bar $=20 \mu \mathrm{m})$; (b) detail of striae with 2 rows of poroids and simple vela $(\mathrm{bar}=0,2 \mu \mathrm{m})$. Fig. 3. P. multiseries (a) whole valve, central interspace absent (bar $=20 \mu \mathrm{m})$; (b) detail of striae with 4 rows of poroids and simple vela $(\mathrm{bar}=0,2 \mu \mathrm{m})$. Fig 4. P. fraudulenta (a) valve at low magnification with detail of valve ending (bar $=5 \mu \mathrm{m}$ ); (b) detail of the middle portion of the valve showing central interspace (arrow) and striae with 2-3 rows of poroids with sectored vela (bar $=0,2 \mu \mathrm{m})$.
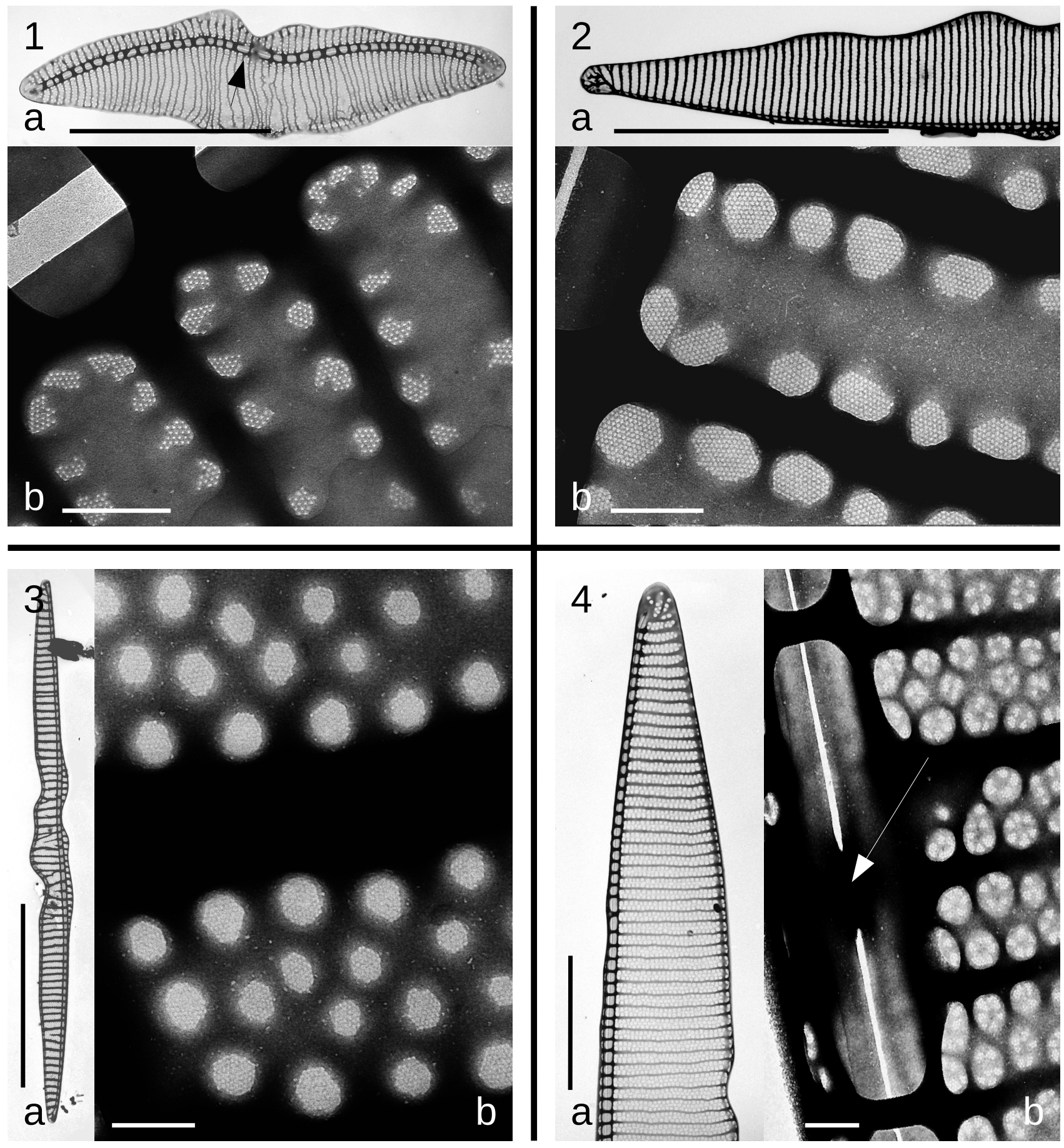